\title{
Research on the Human Resource Management Mode based on Competency Model
}

\author{
Meilin $\mathrm{Yu}^{1}$ \\ ${ }^{1}$ Sichuan Information Technology College , \\ 628017 ,China
}

\begin{abstract}
In this paper, we conduct in-depth research on the human resource management mode based on competency model. Treatment of competency is defined based on the previous scholars, this paper defines enterprise top management competency as can change the performance is outstanding person in senior management positions in companies and generally do distinguish individual potential. Corporate culture has a strong and lasting soft binding, plays an important role in modern enterprise management. The numerical analysis supports the effectiveness and feasibility of the model. In the future, we will conduct more related work to optimize the current theory.
\end{abstract}

Keywords: Human Resource; Business Management; Competency Model; Literature Review.

\section{Introduction}

Over the years since, competency theory greatly promote the progress of the human resource management, provides a theoretical basis for its development, competency theory to promote the old human resources management mode to the new changes in human resource management mode. New based on the competency of human resource management mode focuses on the employee's competency, filtered to employees and to leave a good staff, such as performance evaluation for employees to realize self-worth, so enterprise also can get a better development. Senior managers' comprehensive quality is one of the main factors influencing the management behavior and organizational performance, mainly reflected in the managers' competency

\author{
Duo Xiao $^{1}$ \\ ${ }^{1}$ Sichuan Information Technology College , \\ 628017 ,China
}

characteristics. Only match the organization's strategic goals and job requirements of competency characteristics, can efficiently use management talents, to achieve the organization's long-term goals. Management competency characteristic analysis, and therefore, it has been the human resource management and management psychology research and application of a focus.

Management personnel's comprehensive quality is one of the main factors influencing the management behavior and organizational performance, these qualities ultimately reflected on the competence of management. Only match the organization's strategic goals and job requirements of competence characteristics, management ability can be efficiently and achieve the organization's long-term goals. Competency also gradually as a supplement to the traditional theory of human capital, has greatly helped enterprise analysis about the present situation of management ability and performance improvement of prediction which can be widely used in enterprise's selection, training, evaluation and incentive mechanism. It becomes the organization sustainable competition and the key indicators of enterprise performance. So the enterprise competence of top management to improve the work performance has very important practical significance [1].

Corporate culture has a strong and lasting soft binding, plays an important role in modern enterprise management. Scholars generally believed that the enterprise culture is the enterprise formed for a long time, is a part of the enterprise core competitive ability which is an important source of enterprise competitiveness. 
Enterprise culture because of its enormous influence and enterprise and the attention of scholars, the enterprise culture management as a kind of new management idea, management model was proposed. Enterprise culture infiltration in each aspect which can effectively promote enterprise management ability, it improves the corporate reputation and competitiveness, so the enterprise culture by the modern enterprise concern and attention. Human resources management theory in recent decades have made significant progress, enterprise culture infiltration in enterprise management aspects, including human resources management, so the human resource management practices can use the influence of corporate culture, and contribute to the formation of excellent enterprise culture. Worker productivity and the decline of the industrial innovation is increasingly serious, the traditional human resource management hit hard and huge challenges. All these changes forced scholars and enterprise managers to ponder the source of enterprise competitive advantage, many scholars began to seek the sources of competitive advantage from the enterprise internal, has formed on the basis of the resources, on the basis of ability, based on the knowledge of endogenous competitive advantage theory, thus, as a knowledge, the capability of carrier was improved, the importance of human resources and human resources management theory has gained development.

In this paper, we conduct in-depth research on the human resource management mode based on competency model [2]. Modern enterprise is developing rapidly, the enterprise's environment is in constant change, is now widely used defect patterns of human resource management is becoming more and more prominent, so now the urgent need to develop a new mode of human resource management. Based on the competence theory of American psychologist puts forward management model is gradually rises. In the figure one, we show the principles of the competency model.

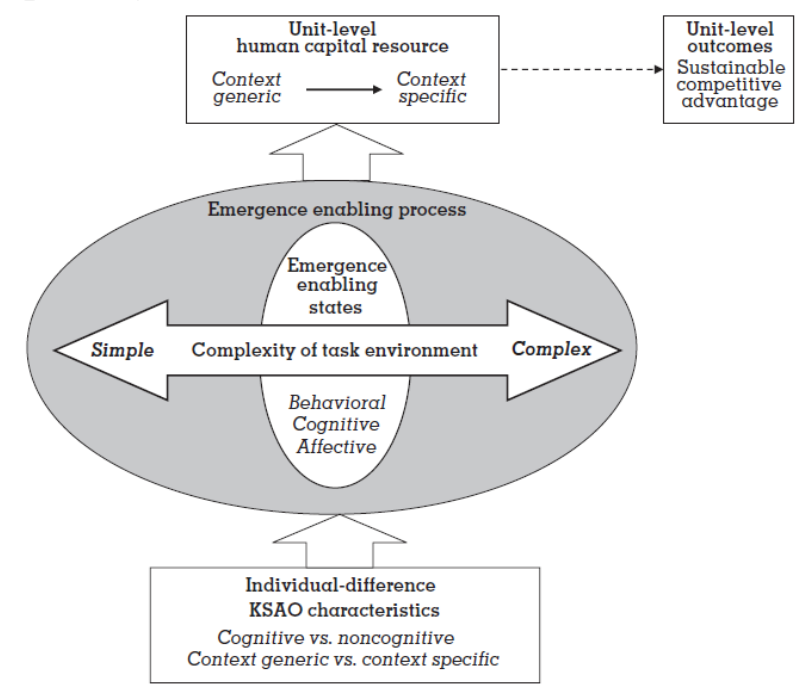

Figure 1. The Flowchart and Principles of the Competency Model

\section{The Proposed Approach and Theory}

The Traditional Human Resource Management. Evaluation of human resource management has always been a more divided area, as the multinational enterprise scale expands unceasingly and some foreign scholars began to study the comprehensive evaluation of human resource management, after several years of development, people gradually has some comprehensive evaluation method. In-depth study on the macro structure mainly from the level of organization, the more is how to realize the enterprise or unit through human resources management of organizational goals and strategic adjustment, how to use more reasonable management model to improve the efficiency of the enterprise. Pay more attention to the study of a function and the micro aspect, mainly is the study of individual, at the individual level management research, focus on how to influence the overall efficiency through management personal [3]. The division of the macro structure of human resource management mainly includes two aspects: strategic human resource management structure and power structure of degeneration of human resource 
management. Microscopic structure of human resource management is divided into: human resource planning, recruitment and evaluation, training and development, compensation management and performance evaluation.

Relations practice, after all, is not the predominant thought that the enterprise human resources management, but the relationship orientation in the modern enterprise management episodic manifestations. Employees in the face of such an objective phenomenon, can be in cognitive level on the basis of different depth affected by the traditional culture make difference of judgment. A collection of individual level judgment and awareness of these events which can be formed group atmosphere. Organizational justice is implemented in this kind of atmosphere and staff awareness.

Human resource management activities by building the human resource management system, the system to reflect the characteristics of corporate culture, to support and guarantee for the enterprise culture. Through the guide of employee behavior, constraints and incentive choice, abandon and strengthen enterprise culture constantly. The human resources management is the process of shaping process of the enterprise culture, through a series of continuous and objective of human resource management activities to form the enterprise culture system, and become the utility function of enterprise culture foundation. Human resource management policies and institutions often have a mandatory, employees in the dayto-day work under the mandatory guidance and constraint, and in the process of the constantly adjust and correct your behavior and idea, and was perfected, consolidate and strengthen the enterprise culture. Through effective human resource management, fully tap the potential, in the enterprise internal form good atmosphere which will largely increase and enhance the staff to enterprise's sense of belonging and identity [4].
The Competency Model based Human Resource Management. At home and abroad at present, the definition of competency is not unified and the scholars have also has their own understanding and awareness. Treatment of competency is defined based on the previous scholars, this paper defines enterprise top management competency as can change the performance is outstanding person in senior management positions in companies and generally do distinguish individual potential, deep features. We can from the definition of competency, competency characteristic mainly distinguish between individuals in certain organization environment and performance of a specific job level of personal characteristics which could be summarized as the follows. (1) Knowledge refers to a person for a particular have known and master the information. (2) Skills refer to a person when performing a specific task of the skills and abilities. (3) Selfconcept is an organic cognitive structure, is the experience of one's own existence. (4) Motivation refers to a person under the guidance of a specific target or object, pushing its goal of will and faith, so as to propel themselves to make a choice and action. From the perspective of management, work performance is expected to pursue the ultimate goal of organization as a result, is to achieve the goal in the embodiment of the different level and output. It is truly inspection enterprise strategy, the core of strategic management.

It is also direct embodiment of enterprise competitiveness and reflects the status of the enterprise in the process of development and market position. At the time of performance assessment, to require employees with competency standards, not only can make employees can clear development goal of their jobs makes clear its own efforts in the direction of the employees, the process and also in the enterprise is often used in the link of human resource management training links are closely related. Based on competency training, the goal is more evident, the task is more detailed, more 
training according to the target. In enterprise training must first establish competency model, and according to the requirements of the position to set up the reasonable training plan, finally the result of the training and assessment, will be based on the competency of performance evaluation of the effect to the limit.

Inherent in the individual's competency sort very much, but in the concrete work environment and specific jobs is not needed for all individual competence. Required by the organization's competency is according to the specific jobs as well as the specific organizational environment requires the ability, to ensure that employees are qualified for the job, and to give full play to their maximum potential competency characteristics. Need competence in an organization is the individual with some of the qualities and abilities, proved in certain jobs and specific organizational environment that met the need of the work of some specific activities. Competence can be predicted roughly one future work performance, can be good, and apart from the ordinary people and that part can be called competency's ability to distinguish between them. Competency is different in different positions, with their jobs, there is a difference between the different is associated with tasks and jobs. Therefore, the relationship of management and the model could be summarized as the follows. (1) Differences between competency characteristics lead to different performance prediction effect different effects. (2) Management competency characteristic consists of management quality and management skills in two dimensions, but in the concrete, the elements of different levels of managers with different structural elements. (3) Competency characteristics and there exists a very close relationship between the performance and competence is one of the factors that determine your work performance, and there is the question of both complex structure. (4) Based on the competency of career planning can not only arouse the enthusiasm of the employees, also can be helpful for the sustainable development of the enterprise. In the process of formulation of competency model, enterprise to guide its employees in line with their own career planning, so for employees to realize the value of the self and also can make staff to work hard to improve performance, the enterprise can get development, make the staff and enterprise win-win, and long-term development.

The Combination of the Model. Including the contents of different post competency is different, this is also reflected the competency of the characteristics of the post-match. Today, competency theory also in each big enterprise human resources management system played a very important role, and has been widely used. When a particular job, the job needs comprehensive all capabilities are called competency model. To construct the competency model is also varied and the content of the competence is also very rich. In the process of building competency needs to follow certain process, first of all want to make sure of the positions to be analysis, to determine the standard and sample according to the standard analysis, analysis done to choose some samples and then to summary, finally to refine competence elements, by extraction with elements of constructing competency model, further build good after the preliminary model correction, finally determine the competency model of the position. Long-term building competency model will form a competency model database, which will lay a foundation for the long-term development of the enterprise. Competency model can not only as a kind of management thought, or is a kind of management concept and it is still for enterprise human resources management is effective management tool, the future of human resource management work will be largely tend to the study of competency theory. 


\section{Conclusion}

In this paper, we conduct in-depth research on the human resource management mode based on competency model. As the conventional force resources management basic type with auxiliary role positioning which are partial light executive decisions rarely participate in organizational innovation strategy decision-making and the requirements of the innovation mode for the construction of integrated into the design of the human resources strategy, basically just after the event evaluation on enterprise innovation behavior. Because there is no innovation strategy according to the enterprise overall strategic planning, dig new achievements nor audit according to the enterprise value chain, often causing unstable phenomenon, independent innovation strategy of the enterprise to enterprise business performance improvement. Our proposed method could enhance the human resources management and level-up the staffs' passion on working which will be meaningful.

\section{References}

[1] Zhang K K, Yi-Qun L I. On the Mode of Police Human Resource Management Based on Competency[J]. Journal of Shandong Administration Institute \& Shandong Economic Management Personnel Institute, 2010.

[2] $\mathrm{Xu}$ F. College Human Resource Management System Based on Competency Model[J]. Computer \& Digital Engineering, 2010.

[3] Juan L I, Huang Q. Application of the process of human resource management-based on competency model[J]. Technological Development of Enterprise, 2011.

[4] Zhang L X. Design and Implementation of Coal Enterprise Human Resource Management System Based on B/S Mode[J]. Coal Technology, 2013. 